\title{
To Pivot or Not To Pivot: On the Relationship between Pivots and Revenue among Startups
}

\author{
Cesar Bandera \\ Martin Tuchman School of Management \\ New Jersey Institute of Technology \\ bandera@njit.edu
}

\author{
Ellen Thomas \\ Martin Tuchman School of Management \\ New Jersey Institute of Technology \\ ellen.thomas@njit.edu>
}

\begin{abstract}
The concept of the pivot, whereby a new venture alters its offering or business model, is standard practice among new ventures seeking to validate their value proposition in uncertain markets. Whereas a new venture begins with a business model driven by the entrepreneur's perception of the market, pivots driven by market feedback align the venture with market need. However, we argue that executing too many pivots can adversely affect firm performance by postponing the maturation of the firm. Using change in a venture's NAICS code as a proxy for pivoting, we show an inverted- $U$ relationship between revenue and the number of pivots among Kauffman Firm Survey participants. This longitudinal empirical study is one of the first on the relationship between pivoting and performance. It aims to attract attention to this important topic of entrepreneurship, and help the entrepreneur facing the difficult decision of whether or not she should pivot.
\end{abstract}

\section{Introduction}

Entrepreneurs managing high degrees of uncertainty are often faced with the choice of staying committed to their original business model or pursuing a new direction. There are two ways entrepreneurs can change direction. They can learn and change incrementally by varying a single element of their business model. Alternatively, they can make a radical change to their strategy by changing multiple elements of their business model [1]. The decision to continue with the current strategy or pivot away from it is one of the hardest decisions that entrepreneurs will face [2].

The term "pivot" has become part of the everyday language of entrepreneurs and those who advise and fund them. It was first coined in 2009 [3] and is defined as "a structured course correction designed to test a new fundamental hypothesis" [2] (pg 149). Although the term is relatively new, it is closely related to the concept of business model innovation in that it defines a broad range of change related behaviors.

Pivoting is promoted and celebrated in the entrepreneurship literature with anecdotes often told of successful pivots. For example, Groupon began as a dogood site called The Point, PayPal started as cryptography libraries for Palm Pilot devices, YouTube started as a video-dating site, and Twitter began as a platform to subscribe to podcasts [4].

There are many reasons an entrepreneur would decide to pivot. Clearly, staying with a business idea that is not working could have severe consequences, particularly for a start-up which is often focused on a single project. Project failure in this case can put the entrepreneur out of business. Questioning initial lowpotential business models and refining them helps entrepreneurs discover and assess multiple alternatives, gather valuable information, and make better decisions [5]. Failure followed by pivoting is often treated positively as a validated learning process [2, 3]. Research has also found that business model viability is greatly improved by business model experimentation. For example, pivoting is the most frequently occurring commonality among different successful startups [2] and committing too early to a specific business model can have negative effects on long-term survival and performance [1].

However, pivoting is not a guarantee for success especially when changing direction can consume resources and move entrepreneurs away from competencies. For example, as entrepreneurs build their businesses they become increasingly knowledgeable in the associated processes, technologies and markets. They may lose that expertise during a pivot resulting in lost time and resources [6].

The importance of pivoting to entrepreneurs deserves research attention and currently there is a gap in our understanding. Prior work tends to be conceptual [7-9], qualitative $[1,10]$, or quantitative in the context of established firms [11, 12]. Nascent research on startup pivots focus on antecedents, i.e. what triggers a pivot, such as feedback, entrepreneur characteristics, 
environmental factors, or investment [6, 13, 14]. In general, existing research and knowledge on pivots is limited and there has been a call for better understanding of business model development in new venutres $[5,13]$.

This study fills the research gap in a number of ways. First, we use the Kauffman Firm Survey longitudinal dataset to empirically investigate the relationship between startup success and its pivot activity. Second, recent studies of pivot activities $[13,14]$ noted that often a firm engages in multiple pivots. Given the fact that pivots can redirect a failing business model but at the same time consume scarce resources, we investigate if there is a threshold to the number of pivots a firm can make after which pivots become detrimental to performance. Finally, while research on startup pivots is generally done in the context of high-technology we study the moderating effect of high-tech versus low-tech startups. Frequent testing, tweaking and pivoting may be viable for websites, apps, or other digital products that can be addressed by coding changes but not traditional manufactured goods.

Entrepreneurs need to be persistent when facing adversity and skepticism. However they must also be flexible enough to leave behind some of the ideas in which they invested, and explore different opportunities [6]. To the best of the authors knowledge, this study is the first of its kind to address the issue of successive pivoting, product type, and startup survival.

\section{Framework and Hypotheses}

Pivot is a recent term and literature definitions include phrases such as "change course", "shift in strategy", or "adapting the business model". In other words, pivot is often considered synonymous with change. More specifically, it is considered as validating a hypothesis related to a business model $[2,15]$ and is often considered the path entrepreneurs must take when looking for the correct strategy.

Ries [2] offers ten different types of pivots that startups can make such as pivots based on product, customer segment and need, platform, business architecture, value, engine of growth, channel, and technology. In a study of the software industry, the most common external trigger of a pivot was negative customer reaction, and the most common internal trigger of a pivot was a flawed business model [13].

Some pivots can be incremental where a small element of the product, service, or business model is changed. Other pivots can be radical where significant and possibly multiple elements of the business model are changed [1]. While it is often argued that successful startups must make multiple pivots [16] and pivots are often used in a continuous process of validating hypotheses, the focus of this study is not incremental change. Instead, our focus is on radical pivots that are so significant they cause a change in the startup's North American Industry Classification System (NAICS) code. For example, Android began as an operating system for cameras and pivoted to the smartphone industry. Flickr was a role playing game that pivoted to a photo sharing service [13]. Like continuous incremental change, radical pivots can lead to long term growth, but unlike continuous incremental change, radical pivots are disruptive to the startup and are not as well understood [1].

Startups are under conflicting pressure to cut losses and execute changes rapidly, or stay the course and give its business model time to succeed and attain legitimacy. Cutting losses and making changes, i.e. choosing to pivot, is often intuitive. Staying with a business model when there are negative responses from customers, unanticipated competitive pressures, or technical challenges can lead to business failure. Using new information reduces uncertainty and helps firms find better business opportunities. Startups often need to make multiple pivots. For example, MishGuru began as a company that let users design and print their own horseshoes. This idea was not scalable because horse owners were not conducive to rapid growth. They pivoted to a collaborative video making site and finally ended up as a successful content management system for SnapChat. RetentionScience initially provided independent artists a platform where they could promote niche brands and products via social media. This business model proved not to be scalable so it pivoted to providing a social media-based analytics and referral platform for e-commerce businesses. However, because they encountered many well-funded competitors working in the same area, they pivoted again towards a retention automation platform that makes AI accessible to business clients.

Despite the reasons for pivoting, there are also many reasons a startup may decide to persevere and stay the course. Focused commitment to the original business plan can positively impact initial growth [1] because entrepreneurs learn quickly about technical and market issues while staying ahead of competitors. As entrepreneurs build their businesses, they become experts on associated processes, technologies, and markets. In such cases, expertise that has taken time and resources to develop can be lost with a radical pivot. In other cases, the business model is valid but requires longer time to achieve milestones like the first paying customer, revenue, or profit. Furthermore, having one clear value proposition for stakeholders allows a firm to better attract strategic partners and valuable employees [1]. Pivots can harm an entrepreneur's and creative employees' ownership of their original idea thereby 
undermining any attempts at change [17]. It would also mean changing the mindset of all stakeholders, specialized employees, organizational structures, and dealing with missing competencies.

Staying the course also avoids some of the hazards of successive pivoting. One study found that firms can have considerable difficulties in mobilizing stakeholders and additional resources for subsequent pivots leading to bankruptcy in several cases [1]. Investors are not always supportive of continued change and refrain from injecting large amounts of capital until progress has been made. Successive radical pivots can also weaken investor commitment because they begin to question whether the business model was wrong or the problem lies with the entrepreneurs [18].

Staged models of new venture evolution [19], including the "Valley of Death" model [20, 21], predict that firms initially endure a period of time with no revenue while they validate their value proposition, pivoting when necessary. This pre-revenue period is followed by a post-revenue period with some initial sales that validate the value proposition, but are insufficient to cover expenses. During this post-revenue pre-break-even period, ventures change their focus from innovation to operational efficiency in order to achieve profitability (the third period). The pivoting activity of startups occurs primarily in the first phase, where success is measured by revenue, not profit. Consequently, we use revenue as a measure of pivot success.

Given the conflicting pressure to pivot and persevere, we hypothesize that the value of pivoting will initially grow with each change but eventually diminish as redefining the business model becomes more costly or as resources run dry, leading to an inverted-U relationship between firm performance and the number of pivots:

H1: The revenue of a new venture exhibits an inverted-U relationship with the number of pivots.

An entrepreneur's need to pivot most commonly originates from mistaken assumptions of the target market and, by extension, the new venture's value proposition. The uncertainty of markets and value propositions is characteristically higher in the high tech startup domain than in general. Consequently, the need for pivots to disambiguate this uncertainty is even more critical in the high tech startup domain. While pivoting in software based industries is most often researched and celebrated, it is also possible in more traditional industries. However, while testing and tweaking of websites and apps is often done by simply modifying code, pivoting in other sectors is generally considered to be much more difficult, see [22, 23]. For these reasons, we hypothesize:

H2: The relationship between revenue and pivots is different between high-tech firms and low-tech firms.

\section{Methods and Data}

In this study, we consider a pivot to be a significant change in a firm's business model, as opposed to an incremental change such as altering a feature in a firm's product or service. Because a change to a firm's North American Industry Classification System (NAICS) code would indicate such a significant change, we use a change in the NAICS code to reflect a pivot. Moreover, we represent revenue as a binary variable and not as a continuous variable for two reasons. First, the success of pivoting is not so much the amount of revenue but the existence of any which in turn reflects business model validation. Second, revenue varies by orders of magnitude between industries, and we seek to control for this variance.

This study uses the Kauffman Firm Survey (KFS) of 4928 companies founded in 2004 and surveyed annually from 2004 to 2011 [24]. The KFS collects information about each participating firm's business characteristics, strategy and innovation, business organization and human resource benefits, business finances, work behavior, and ownership and demographics of its active owner and operators. Specifically, the study uses the confidential longitudinal long-format KFS dataset (KFS8_L_L1) hosted by the National Opinion Research Center (NORC) Data Enclave for the Kauffman Foundation [25]. Unlike the public version of the KFS which provides only the leftmost two digits of each firm's NAICS code (i.e., the firm's sector code), the confidential dataset provides all six digits, enabling the study to detect more subtle pivots that impact the less significant digits.

Because the KFS collects data once a year, we can detect one change annually in a firm's NAICS code, and the response to the question: "In calendar year [20XX], did [BUSINESS NAME] receive any revenue from the sales of goods, services, or intellectual property?” for each year between 2004 and 2011 inclusive. Thus, for each year we have the revenue status of the surviving responding startups, and can compute the total number of pivots (NAICS code changes) that preceded that revenue status. The KFS also reports if each participant, at each year, considered itself to be a high-tech firm or not.

Table 1 presents the summary statistics of the KFS data employed in the study viewed per year. It shows the typical exponential decrease in surviving firms, and 
that firms in general pivot (radically) early in their lifecycle. There are no pivots detected in 2004 because that is the first year of the KFS.

Table 2 presents the summary statistics of the KFS data employed in the study viewed per number of pivots. It indicates a non-linear relationship between the odds of revenue at any particular year, and the number of pivots the startup executed up to and including that year. An inverted-U relationship is illustrated in Figure 1 by the quadratic trendline of revenue versus number of pivots, which is more pronounced among high-tech firms.

Table 1. Summary statistics of survivorship and pivot activity.

\begin{tabular}{|c|c|c|c|c|c|c|}
\cline { 2 - 7 } \multicolumn{1}{c|}{} & \multicolumn{3}{c|}{ High Tech } & \multicolumn{2}{c|}{ Low Tech } \\
\hline Year & $\begin{array}{c}\text { Surviving } \\
\text { Firms }\end{array}$ & Pivots/Year & $\begin{array}{c}\text { Cumulative } \\
\text { Pivots/Firm }\end{array}$ & $\begin{array}{c}\text { Surviving } \\
\text { Firms }\end{array}$ & $\begin{array}{c}\text { Cumulative } \\
\text { Pivots/Year } \\
\text { Pivots/Firm }\end{array}$ \\
\hline 2004 & 417 & $0.00 \%$ & 0.00 & 2723 & $0.00 \%$ & 0.00 \\
\hline 2005 & 377 & $23.87 \%$ & 0.24 & 2407 & $24.18 \%$ & 0.24 \\
\hline 2006 & 310 & $20.97 \%$ & 0.40 & 2158 & $24.42 \%$ & 0.49 \\
\hline 2007 & 272 & $4.78 \%$ & 0.43 & 1932 & $8.44 \%$ & 0.57 \\
\hline 2008 & 264 & $10.98 \%$ & 0.59 & 1767 & $8.77 \%$ & 0.64 \\
\hline 2009 & 249 & $0.80 \%$ & 0.59 & 1627 & $4.06 \%$ & 0.69 \\
\hline 2010 & 235 & $2.98 \%$ & 0.66 & 1499 & $3.40 \%$ & 0.71 \\
\hline 2011 & 216 & $1.85 \%$ & 0.64 & 1401 & $3.28 \%$ & 0.75 \\
\hline
\end{tabular}

Table 2. Summary statistics of pivot and revenue performance.

\begin{tabular}{|c|c|c|c|c|c|c|c|c|}
\hline \multirow[b]{2}{*}{ \# of Pivots } & \multicolumn{4}{|c|}{ High Tech Startup Years } & \multicolumn{4}{|c|}{ Low Tech Startup Years } \\
\hline & Total & No Revenue & Revenue & $\%$ Revenue & Total & No Revenue & Revenue & \% Revenue \\
\hline 0 & 1782 & 318 & 1464 & 82.2 & 11088 & 2376 & 8712 & 78.6 \\
\hline 1 & 234 & 49 & 185 & 79.1 & 2015 & 393 & 1622 & 80.5 \\
\hline 2 & 283 & 44 & 239 & 84.4 & 2059 & 333 & 1726 & 83.8 \\
\hline 3 & 23 & 4 & 19 & 82.6 & 178 & 21 & 157 & 88.2 \\
\hline 4 & 13 & 7 & 6 & 46.1 & 57 & 9 & 48 & 84.2 \\
\hline 5 & 2 & 2 & & 0 & 32 & 8 & 24 & 75 \\
\hline 6 & & & & & 4 & & 4 & 100 \\
\hline
\end{tabular}

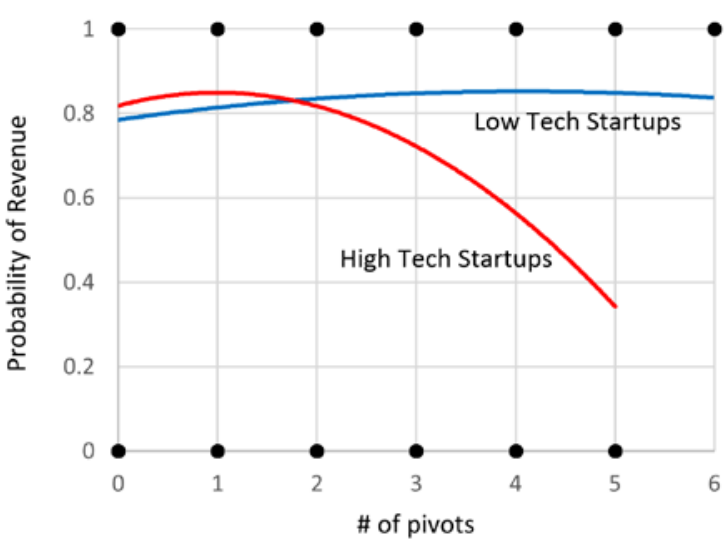

Figure 1. Trend lines of revenue vs. pivots.

To test the hypotheses, we model revenue as a binary outcome and perform a quadratic logistic regression, using the number of pivots and the number of pivots squared as covariates. The odds ratio of a firm $j$ achieving revenue in year $t$ is thus modeled as

$$
O R_{j, t}=e^{\text {logit }}=\exp \left(\beta_{0}+\beta_{1} p_{j, t}+\beta_{2} p_{j, t}^{2}\right)
$$

where $\beta_{i}$ is the $i$ 'th order coefficient of the logit, and $p_{j, t}$ is the number of changes to NAICS code (i.e. pivots) the firm has reported since its inception up to and including year $t$.

\section{Results}

Table 3 presents the results of the quadratic logistic regression of achieving revenue over number of pivots. In all cases (high tech, low tech, and combined), the coefficient of the second order term is negative, indicating an inverted-U relationship. The magnitude of the second order coefficient is greater among high tech firms, indicating that revenue is more sensitive to pivoting (the steepness of the curve in Figure 2 is greater) among high tech firms than among low tech firms. The two hypotheses are thus supported. 
Among high tech firms, the odds ratio of achieving revenue is highest after just one radical pivot, whereas among the general cohort the odds ratio is highest after three radical pivots. Among low tech firms, the odds ratio is highest after four radical pivots, but the second order effect among low tech firms is not statistically significant because the logit curve is relatively flat and insensitive to the number of pivots.

\section{Discussion, Limitations, and Future Research}

This study empirically confirms the inverted-U relationship between performance (probability of achieving revenue) and radical pivots (change in NAICS code) among startups. Being longitudinal the study was able to track the pivoting history of each participating firm and compute the running sum of pivots. The higher sensitivity to pivots (greater logit coefficient magnitude) among high tech firms may be due to factors previously discussed. Because high tech firms operate in greater market uncertainty than low tech firms, they have more to benefit from an initial course correction, which would explain the steep improvement in performance between zero and one pivot. At the same time, too many pivots penalize high tech firms more severely than low tech firms, possibly because the former are more dependent on being perceived by stakeholders as consistent in such uncertainty.
High tech and low tech firms were found to differ not only in the sensitivity to pivoting, but also in the optimum number of radical pivots. The weaker penalty for "over-pivoting" among low-tech firms may explain their higher optimum number of pivots.

There are several limitations to this study. The first is that the KFS does not reveal multiple pivots that may have occurred between annual follow-ups, but only if at least one occurred. A second limitation is the proxy used for radical pivot: a change in the self-reported sixdigit NAICS code. One could argue that a firm could undergo a critical pivot without incurring a change to its NAICS, although an NAICS change would remain being a strong indicator of radical pivot.

This exploratory research can be continued along several directions. The model can be expanded to control for factors that may contribute to sensitivity to pivoting, such as a firm's reliance on investors. Very radical pivots (e.g., a sector change involving the two most significant digits of the NACIS code) can be distinguished from less radical pivots. Moreover, it is possible that different types of pivots occur with different outcomes at different stages of a startup. Blank [15] calls these stages the concept, development, working prototype, and mature product stages. It is possible that hesitation to pivot may increase the longer a firm has been in existence as the firm is more invested in its expertise. It also may be more risk averse, or display more persistence, extreme devotion, or overconfidence.
Table 3. Logistic regression results.

\begin{tabular}{c|cc|cc|cc}
\multirow{2}{*}{} & \multicolumn{2}{|c|}{ High Tech } & \multicolumn{2}{c|}{ All Firms } & \multicolumn{2}{c}{ Low Tech } \\
\cline { 2 - 7 }$\beta_{1}$ & Coeff & Stat Sig & Coeff & Stat Sig & Coeff & Stat Sig \\
$\beta_{2}$ & 0.332 & $\mathrm{p}<0.05$ & 0.219 & $\mathrm{p}<0.01$ & 0.209 & $\mathrm{p}<.001$ \\
& -0.164 & $\mathrm{p}<0.01$ & -0.041 & $\mathrm{p}<0.05$ & -0.024 & $\mathrm{~N} / \mathrm{S}$ \\
& & & & & & \\
pivot & Logit & Odds & & Ldds & & Odds \\
0 & 1.508 & 4.517 & 1.323 & 3.754 & 1.295 & 3.650 \\
1 & 1.677 & 5.348 & 1.502 & 4.489 & 1.480 & 4.394 \\
2 & 1.518 & 4.565 & 1.599 & 4.950 & 1.618 & 5.044 \\
3 & 1.033 & 2.809 & 1.616 & 5.033 & 1.708 & 5.521 \\
4 & 0.220 & 1.246 & 1.552 & 4.720 & 1.751 & 5.761 \\
5 & -0.920 & 0.399 & 1.407 & 4.082 & 1.746 & 5.732 \\
6 & -2.387 & 0.092 & 1.180 & 3.255 & 1.693 & 5.437
\end{tabular}

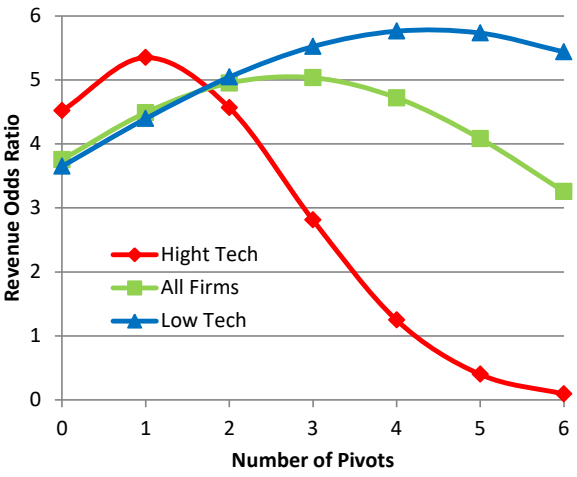

Figure 2. Revenue Odds Ratio versus Pivots.

\section{References}

1. Andries, P., K. Debackere, and B. Looy, Simultaneous experimentation as a learning strategy: Business model development under uncertainty. Strategic Entrepreneurship Journal, 2013. 7(4): p. 288-310.
2. Ries, E., The lean startup: How today's entrepreneurs use continuous innovation to create radically successful businesses. 2011: Crown Books.

3. Ries, E., Lessons learned: Pivot, don't jump to a new vision. 2009. 
4. Arteaga, R., \& Hyland, J., Pivot: How top entrepreneurs adapt and change course to find ultimate success. 2013: John Wiley \& Sons.

5. Leatherbee, M. and R. Katila. Stay the Course or Pivot? Antecedents of Cognitive Refinements of Business Models in Young Firms. in Academy of Management Proceedings. 2017. Academy of Management Briarcliff Manor, NY 10510.

6. Crilly, N., 'Fixation'and 'the pivot': balancing persistence with flexibility in design and entrepreneurship. International Journal of Design Creativity and Innovation, 2018. 6(1-2): p. 52-65.

7. McGrath, R.G., Business models: A discovery driven approach. Long range planning, 2010. 43(2-3): p. 247261.

8. Snihur, Y., B.S. Reiche, and E. Quintane, Sustaining Actor Engagement During the Opportunity Development Process. Strategic Entrepreneurship Journal, 2017. 11(1): p. 1-17.

9. Chesbrough, H., Business model innovation: opportunities and barriers. Long range planning, 2010. 43(2-3): p. 354363.

10. Amit, R. and C. Zott, Value creation in e-business. Strategic management journal, 2001. 22(6-7): p. 493-520.

11. Kim, S.K. and S. Min, Business model innovation performance: When does adding a new business model benefit an incumbent? Strategic Entrepreneurship Journal, 2015. 9(1): p. 34-57.

12. Osiyevskyy, O. and J. Dewald, Explorative versus exploitative business model change: the cognitive antecedents of firm-level responses to disruptive innovation. Strategic Entrepreneurship Journal, 2015. 9(1): p. 58-78.

13. Bajwa, S.S., et al., "Failures" to be celebrated: an analysis of major pivots of software startups. Empirical Software Engineering, 2017. 22(5): p. 2373-2408.

14. Brush, C.G.E., Linda F.; and Manolova, Tatiana S. , To Pivot or Not To Pivot: Why Do Nascent Ventures Change Their Business Models? Frontiers of Entrepreneurship Research, 2015. 35(1).

15. Blank, S., Why the lean start-up changes everything. Harvard business review, 2013. 91(5): p. 63-72.

16. Hirvikoski, K. Startups pivoting towards value. Data and value-driven software engineering with deep customer insight. in Proceedings of the seminar. 2014.

17. Grimes, M., The Pivot: How Founders Respond To Feedback through Idea and Identity Work. Academy of Management Journal, 2017. in press p. amj. 2015.0823.

18. Bhide, A., Bootstrap Finance: the art of start-ups. Harvard business review, 1992. 70(6): p. 109-117.

19. Zacharakis, A., W. Bygrave, and A.C. Corbett, Entrepreneurship. 4th ed. 2017, Hoboken, New Jersey: John Wiley \& Sons, Inc. 610.

20. Verhoeff, A. and H. Menzel, Social capital to bridge the valley of death, simulating critical incidents in innovation. International Journal of Entrepreneurship and Small Business, 2011. 14(1): p. 149-169.

21. Markham, S.K., et al., The Valley of Death as Context for Role Theory in Product Innovation. Journal of Product Innovation Management, 2010. 27(3): p. 402-417.
22. Maine, E., Scientist-entrepreneurs as the catalysts of nanotechnology commercialization. Reviews in Nanoscience and Nanotechnology, 2013. 2(5): p. 301-308.

23. Linton, J.D. and S.T. Walsh, A theory of innovation for process-based innovations such as nanotechnology. Technological Forecasting and Social Change, 2008. 75(5): p. 583-594.

24. Robb, A. and J. Farhat, An Overview of the Kauffman Firm Survey: Results from 2011 Business Activities. 2013, Ewing Marion Kauffman Foundation.

25. Farhat, J.B. and A. Robb, Applied Survey Data Analysis Using Stata: The Kauffman Firm Survey Data. Available at SSRN 2477217, 2014. 